\title{
Presença de condomínios horizontais e loteamentos fechados nas cidades contemporâneas: expansão e transformações do espaço urbano de Teresina, Piauí
}

\author{
Guilhermina Castro Silva* \\ Wilza Gomes Reis Lopes** \\ Maria do Socorro Lira Monteiro***
}

\section{Resumo}

Os condomínios horizontais e loteamentos fechados surgiram como nova proposta de moradia, em que os moradores buscam fugir dos problemas causados pelo crescimento desordenado das cidades, principalmente, os vinculados à falta de segurança, que interferem na qualidade de vida. Neste estudo, objetivou-se discutir o surgimento e a evolução dessa forma de morar e a interferência nas cidades, como fragmentação do espaço social, alterações na estrutura morfológica do tecido urbano, tendo como foco a cidade de Teresina, capital do Piauí. Foi realizado levantamento, mapeamento e caracterização destes empreendimentos, sendo encontrados 11 loteamentos e 57 condomínios fechados, com áreas de diferentes tipologias e tamanhos. Embora, a maioria dos empreendimentos se concentra na Zona Leste, são encontrados nas diversas zonas da cidade, direcionando o crescimento da cidade e a valorização dessas áreas.

** Doutoranda em Desenvolvimento e Meio Ambiente, PRODEMA/UFPI (guilherminacastro@hotmail.com).

**** Arquiteta, Professora do Departamento de Construção Civil e Arquitetura e do Programa de Pós-Graduação em Desenvolvimento e Meio Ambiente, PRODEMA/UFPI (izalopes@uol.com.br).

****** Economista, professora do Departamento de Economia/UFPI (socorrolira@uol.com.br).

Geosul, Florianópolis, v. 30, n. 59, p 167-187, jan./jun. 2015 
SILVA. G.C. et al. Presença de condomínios horizontais e loteamentos ...

Paavras-chave: Moradia; Espaços privados; Segregação espacial; Fragmentação.

Presence of gated communities and allotments closed in contemporary cities: expansion and transformation of urban space in Teresina, Piauí

\begin{abstract}
The gates communities and private gates communities as a new proposal for housing, in that if you are trying to get away from problems caused by the disorderly growth of cities, among them the lack of security and quality of life. This article presents a theoretical discussion on the emergence and development of condominiums and subdivisions closed and how this has changed the cities, affecting the fragmentation of the social space and changing the morphological structure of the urban fabric, with focus on city of Teresina, capital of Piauí. Through on-site visits was collected the coordinates of these ventures and done photographic records. Currently, in Teresina there are 68 projects, of which 11 blends closed and 57 gated communities. The majority of these ventures is present in the Eastern Zone, but are also present in other areas of the city.
\end{abstract}

Key words: Dwelling; Private Spaces; Spatial segregation; Fragmentation.

\title{
Introdução
}


SILVA. G.C. et al. Presença de condomínios horizontais e loteamentos ...

A população do Brasil tem se tornado predominantemente urbana, com mais de $80 \%$ dos habitantes residindo nos aglomerados urbanos. O crescimento das cidades vem acompanhado de problemas como excesso de lixo, inundações, poluição do ar, ilhas de calor, carência de habitações e falta de segurança, dentre outros. Desde os primórdios da humanidade, a habitação que representa segurança e abrigo, sempre representou uma das necessidades básicas para o homem.

As pessoas com renda mais elevada procuram por moradias mais afastadas das áreas centrais, buscando melhor qualidade de vida e segurança como atributos principais. A imagem dos condomínios horizontais fechados, vendida nas campanhas publicitárias, geralmente, está vinculada a um local seguro, com espaços livres de uso comum, presença de área verde, de áreas de lazer, de equipamentos, serviços e com homogeneidade e status social. Procura-se, dessa forma, morar com segurança, sem abrir mão do conforto de residências unifamiliares.

Os condomínios horizontais fechados são considerados uma nova forma de segregação urbana contemporânea, devido ao muro que cerca e separa a área pública da particular. Geralmente, de grandes extensões, estão localizadas em áreas afastadas dos centros urbanos, urbanizadas e isoladas do seu entorno, fazendo parte do processo de reestruturação do padrão residencial em que o uso é restrito aos moradores. Essa nova maneira de morar teve início nos Estados Unidos (gated communities) e, atualmente, é possível encontrá-la em várias cidades ao redor do mundo.

No Brasil, os condomínios horizontais fechados surgiram na década de 1970, para as classes alta e média em ascensão, com a construção do Alphaville, na cidade de São Paulo. Atualmente, são encontrados em todo território brasileiro como um novo estilo de vida, constituindo um verdadeiro "paraíso" para a especulação imobiliária (CALDEIRA, 2003).

A cidade de Teresina, capital do estado do Piauí, de acordo com o censo de 2010 , tem 814.230 habitantes e área de $1.756 \mathrm{Km}^{2}$. Considerando a faixa de renda por domicílio, $62,18 \%$ possuem renda 
SILVA. G.C. et al. Presença de condomínios horizontais e loteamentos ...

menor que 1 salário mínimo, enquanto apenas 3,81\% dos domicílios têm renda entre 5 a 10 salários mínimos e, apenas, 1,56\% dos domicílios possuem renda acima de 10 salários mínimos (IBGE, 2010). Trata-se de uma cidade cuja expansão territorial conta com empreendimentos habitacionais de médio e grande porte.

Neste artigo, discutiu-se o surgimento e a evolução dos condomínios horizontais e loteamentos fechados e como isso tem modificado as cidades, afetando a fragmentação do espaço social e alterando a estrutura morfológica do tecido urbano, tendo como enfoque a cidade de Teresina, Piauí.

Para identificar, mapear e caracterizar os condomínios e loteamentos fechados, existentes na cidade de Teresina, foi realizado, levantamento em jornais e classificados de imóveis no Arquivo Público do Estado do Piauí e em sites de imobiliárias, até novembro de 2014. Foi, também, coletado material gráfico de divulgação destes empreendimentos distribuídos pelas imobiliárias, visando quantificá-los e localizá-los, identificando, ainda, o número de unidades de cada empreendimento. Após o levantamento, foi utilizado o GPSMAP 75S, para obter as coordenadas em Universal Transversa de Mercator (UTM), visando elaboração do mapa de localização desses empreendimentos.

\section{Expansão territorial e transformações do espaço urbano}

A cidade pode ser considerada resultado da ação do homem sobre o meio físico. Ao produzir e utilizar o espaço urbano o homem transforma, em curto espaço de tempo, a fisionomia dos lugares com o desenvolvimento da tecnologia e modifica a paisagem que reflete num determinado momento a história da relação homem/natureza, que se altera em razão dos usos que a sociedade faz desses espaços. Segundo Rolnik (2008, p. 4), o espaço metropolitano da Era Industrial transformou e expandiu a zona rural, "redefinindo as fronteiras urbanas como condomínios, hipermercados e shopping centers". Esses lugares fechados com segurança eram considerados seguros em relação aos espaços públicos abertos. 
SILVA. G.C. et al. Presença de condomínios horizontais e loteamentos ...

De acordo com Corrêa (1989, p. 11), o espaço urbano é “[...] um produto social, resultado de ações acumuladas através do tempo, e engendradas por agentes que produzem e consomem espaço". Os agentes produtores do espaço urbano são os proprietários dos meios de produção, proprietários fundiários, promotores imobiliários, grupos sociais excluídos e o Estado. $\mathrm{O}$ autor conclui que o espaço urbano se apresenta fragmentado e articulado, um campo de lutas de uma sociedade potencialmente conflitante, envolvendo mitos e valores projetados em suas formas espaciais.

A expansão urbana cria novas áreas para moradia, distantes das áreas centrais e que, atualmente, atraem empreendimentos de alto padrão. Com isso, os incorporadores imobiliários objetivam maior renda de suas propriedades, principalmente com o uso comercial ou residencial de status.

Os condomínios horizontais fechados fazem parte de uma reestruturação do padrão residencial e são considerados produto imobiliário, fazendo parte de uma nova configuração socioespacial propiciando novas relações socioespaciais. Na visão de Blakely e Snyder (1997), os gated communities, nos Estados Unidos e os condomínios horizontais, no Brasil, representam o declínio da convivência das diversas classes sociais, em que somente os integrantes das mesmas classes frequentam, caracterizando, assim, a fragmentação social. Dessa forma, nos últimos anos, com a expansão dos condomínios horizontais, têm ocorrido transformações no espaço urbano com as mudanças/segregações espaciais.

\section{Condomínios horizontais e loteamentos fechados e suas particularidades}

Os condomínios horizontais fechados tiveram início nos Estados Unidos onde, segundo Blakely e Snyder (1997), os moradores dos condomínios queriam se isolar dos problemas causados pelo crescimento da industrialização urbana. Isso favoreceu a expansão desses empreendimentos no mercado de 
SILVA. G.C. et al. Presença de condomínios horizontais e loteamentos ...

habitação, especialmente nas áreas recentemente urbanizadas (LE GOIX, 2004).

Historicamente, o condomínio fechado surgiu no pós-guerra com o planejamento urbano realizado, inicialmente, nos subúrbios norte-americanos resultando, segundo Frúgoli Júnior (1995), em uma 'atomização' urbana e nos espaços marcados pela falta de vitalidade nas relações sociais públicas encontradas nas áreas centrais urbanas.

No Brasil, os condomínios horizontais fechados surgiram direcionados para as classes alta e média em ascensão, com a construção do Alphaville, na cidade de São Paulo. Com a expansão desse empreendimento imobiliário, criou-se uma imagem de melhor gestão, prometendo segurança, homogeneidade social, status, paisagem natural e construída e qualidade arquitetural.

Ainda, não há uma legislação federal brasileira para o condomínio horizontal fechado, mas devido à ausência de suporte jurídico se utiliza a Lei 4.591/64, art. $8^{\circ}$ (BARBOSA; COSTA, 2011; BERNARDES; SOARES JÚNIOR, 2007). O condomínio é considerado loteamento sem o ônus urbanístico (implantação de equipamentos urbanos, áreas livres e sistema viário) existentes nos loteamentos regulamentados pela Lei 6.766/79, que destina essas áreas ao Poder Público e a sua espacialidade se limita pela presença do muro ou cerca.

Segundo Souza (2008), os loteamentos fechados são parcelas de terrenos (lotes individuais), em que o proprietário pode utilizálas como lhe aprouver na construção da sua casa. Em relação aos espaços públicos existentes nos loteamentos fechados, o autor considera uma agressão no direito constitucional, como o direito de ir e vir, o direito da intimidade e de reunião. Esses direitos, no loteamento, estão relacionados a um grupo de pessoas dependendo da sua renda.

Para Pinto (2004), as áreas de uso comum nos loteamentos fechados são incorporadas ao patrimônio público, tornando-se objeto de um contrato de concessão de uso entre a Prefeitura e os moradores. Silveira (2011, p. 7) esclarece que municípios não 
SILVA. G.C. et al. Presença de condomínios horizontais e loteamentos ...

podem autorizar loteamentos fechados, porque esses empreendimentos "[...] são fechados por ato do loteador ou de uma associação de moradores, demonstrando a sua ilegalidade”. Souza (2008) conclui que a ausência da figura jurídica do loteamento fechado ocorre com a restrição do acesso aos moradores.

Em Teresina, a lei complementar 3.561/2006 dispõe sobre o parcelamento do solo urbano e contempla no capítulo XII o parcelamento para implantação de loteamentos fechados, em que há permissão do poder público para o fechamento de quadras (TERESINA, 2006).

Para O’Neill (1986, p. 67), os “condomínios exclusivos” são considerados como um conjunto de habitações, que pode ser formado por prédios altos, multifamiliares ou de residências unifamiliares, "isoladas por muros ou cercas da área imediatamente em torno, possuindo policiamento próprio, equipamentos de lazer, algumas ainda outros serviços como, por exemplo, cabeleireiro e restaurante". O autor destaca, ainda, a preferência por situar tais empreendimentos em áreas nobres e locais agradáveis da cidade.

Esses empreendimentos apresentam vantagens em relação a outras áreas urbanas como segurança, amenidades sociais e naturais e valorização do solo. Como impactos negativos têm-se, entre outros, a segregação e exclusão socioespacial, privatização do espaço público, fragmentação e segmentação do tecido urbano, além do enfraquecimento do poder público, em função da privatização dos serviços públicos (BARCELLOS; MAMMARELLA, 2007; CALDEIRA, 2003).

De imediato a segurança é associada ao isolamento físico que esses condomínios proporcionam por meio do muro. Segundo Marx (1980, p. 133), os muros são "instalações especiais reúnem os que se isolam ou os são dos demais isolados. [...] Opostas àquelas que dão acesso ao mundo externo e à vida da cidade, essas instalações cerram suas dependências e seus dependentes". Neste sentido, Bernardes e Soares Júnior (2007) afirmam que o muro é o elemento mais emblemático dos condomínios, que estabelece uma ruptura física ou simbólica no aglomerado urbano. 
SILVA. G.C. et al. Presença de condomínios horizontais e loteamentos ...

$\mathrm{O}$ anseio por segurança é citado como um dos principais motivos para a procura por esse tipo de moradia. Para Sposito (2003, p. 8), os condomínios horizontais fechados são espaços em que se pode prever o que ocorrerá e evitar o indesejável, pois são planejados favorecendo uma valorização no mercado, contrapondose às áreas urbanas, onde a falta de planejamento é marcada pela "heterogeneidade econômica, social, urbanística e arquitetônica".

Segundo Barcellos e Mammarella (2007), a segregação social não é um fenômeno contemporâneo e está associado à existência de classes e grupos sociais diferentes e que se opõem. A segregação socioespacial aconteceu nas cidades gregas, romanas e chinesas, que possuíam divisões socioeconômicas e políticas (NEGRI, 2008). Para Koch (2008, p. 100) além da segregação e das exclusões social e espacial, os condomínios fechados trazem impactos de diferentes níveis no espaço urbano, tais como, "a privatização do espaço público, a perda da vida pública e do significado do espaço público, a fragmentação e a segmentação do tecido urbano, o enfraquecimento do poder público em função da privatização dos serviços públicos, dentre outros".

A segregação é tida como "um processo onde diferentes classes ou camadas sociais tendem a se concentrar cada vez mais em diferentes regiões gerais ou conjuntos de bairros da metrópole" (VILLAÇA, 2001, p. 142). Para Caldeira (2003, p. 258), os condomínios fechados "são a versão residencial de uma nova forma de segregação nas cidades contemporâneas", chamados de enclaves fortificados.

Segundo Castells (1983, p. 210), a segregação residencial é uma "tendência à organização do espaço em zonas de forte homogeneidade social interna e com intensa disparidade social entre elas, sendo esta disparidade compreendida não só em termos de diferença, como também hierarquia". Corrêa (1989) define segregação residencial como uma concentração de tipos de população dentro de um território, que caracteriza a cidade e que sob a égide do capitalismo a segregação assume novas dimensões espaciais e que cada grupo social tem que pagar pela residência que 
SILVA. G.C. et al. Presença de condomínios horizontais e loteamentos ...

ocupa, a qual apresenta características no que se refere ao tipo e à localização (conforto e qualidade).

\section{Processo de expansão e transformações do espaço urbano teresinense}

O Piauí, estado da região Nordeste do Brasil, teve como primeira capital a cidade de Oeiras até o ano de 1852, quando a sede do estado passou a ser Teresina, que foi especialmente planejada com essa finalidade. Segundo Façanha (1998, p. 48), a escolha da localização da nova cidade se deu devido "às condições favoráveis para o uso da navegabilidade do rio Parnaíba, bem como da possibilidade de uma maior articulação entre os principais núcleos urbanos da região, a exemplo de Caxias, no Maranhão".

Nos seis primeiros meses de 1850 , foram construídas as 30 primeiras casas na nova capital e, em 1854, a população total de Teresina era de 8.000 habitantes (GOMES, 1992). Segundo Nascimento (2002), oito anos depois existia 863 residências em Teresina, sendo que 530 eram casas cobertas de palha, revelando que a cidade era um ponto de atração de segmentos pobres do Piauí e de outros Estados.

A cidade se desenvolveu rapidamente como centro administrativo e de comércio varejista. Em 1858, foi fundada a companhia de navegação do rio Parnaíba que originou um porto fluvial de intenso movimento e um centro comercial que atingia a beira do rio para a direção leste da cidade onde se localizavam o mercado público, escritórios, armazéns e casas comerciais (CEPRO, 1992).

Em 1940, apenas 51,3\% da população moravam na zona urbana, enquanto que, na década de 1970 , esse percentual subiu para 82,1\%. Em 1980, a população urbana já era de 91,1\%, chegando a 94,7\%, em 2000 (TERESINA, 2005). Este aumento se deveu ao fato de Teresina ser uma receptora de fluxos populacionais, ao contrário do Piauí, que é caracterizado como fonte de movimento emigratório. 
SILVA. G.C. et al. Presença de condomínios horizontais e loteamentos ...

Nas décadas de 1940 e 1950, ocorreu a expansão da cidade em direção, principalmente, das Zonas Norte e Sul, em decorrência do surgimento dos conjuntos habitacionais, criando-se novos bairros que acabaram alterando a paisagem urbana (VIANA, 2005). Inicialmente, concentrada entre os rios Poti e Parnaíba, Teresina teve seu crescimento seguindo "[...] pela zona Leste por meio da construção da ponte Juscelino Kubitschek, acompanhado da zona Sudeste" (KALLAS, 2008, p. 74).

Em 1951, surgiram os primeiros lançamentos de loteamentos da zona Leste da cidade, como o Socopo e Parque Ceará (CASTELO BRANCO, 2012). Inicialmente, ocupada, segundo Lima (2002, p. 196), "por chácaras de veraneio de famílias mais abastadas", passou a ser a opção escolhida para morar, pelas famílias de maior renda, que abandonaram o Centro, buscando melhor local de moradia (ABREU, 1983).

Esta área da cidade, então, configurou-se como local nobre, em que foram construídas grandes casas em amplos terrenos, atraindo, também, grande parte dos condomínios verticais existentes na cidade.

A zona Leste apresenta uma maior concentração de renda. Dentre os domicílios lá existentes, $52,73 \%$ possuem renda média domiciliar de até um salário mínimo, 9,90\% têm renda entre 5 a 10 salários mínimos e 4,90\% apresentam renda maior que 10 salários mínimos. Enquanto que os bairros da zona Centro apresentam renda, $44,84 \%$ de até um salário mínimo, 6,21\% entre 5 a 10 salários mínimos e 2,3\% com mais de 10 salários mínimos, e os bairros da zona Norte, apenas $0,26 \%$ dos domicílios possuem renda maior que 10 salários mínimos (IBGE, 2010).

Dessa forma, foi Zona Leste que foi implantado, em 1991, o primeiro loteamento fechado, denominado Mansão dos Morros e, também, construído, em 1997, o primeiro condomínio horizontal de Teresina, chamado Jardins de Fátima, localizados, respectivamente, nos bairros Morros e Fátima.

Desde o primeiro lançamento, essa nova forma de moradia foi bem aceita na cidade, sempre aumentado a procura e a oferta 
SILVA. G.C. et al. Presença de condomínios horizontais e loteamentos ...

por estes tipos de empreendimentos, que estão distribuídos em várias partes da cidade, destinados a atender diversos grupos socioeconômicos.

Após a pesquisa, foram localizados, até novembro de 2014, 11 loteamentos fechados e 57 condomínios fechados, em Teresina (Figura 1).

Figura 1: Mapa de localização dos condomínios horizontais e loteamentos fechados, Teresina - Piauí. 
SILVA. G.C. et al. Presença de condomínios horizontais e loteamentos ...

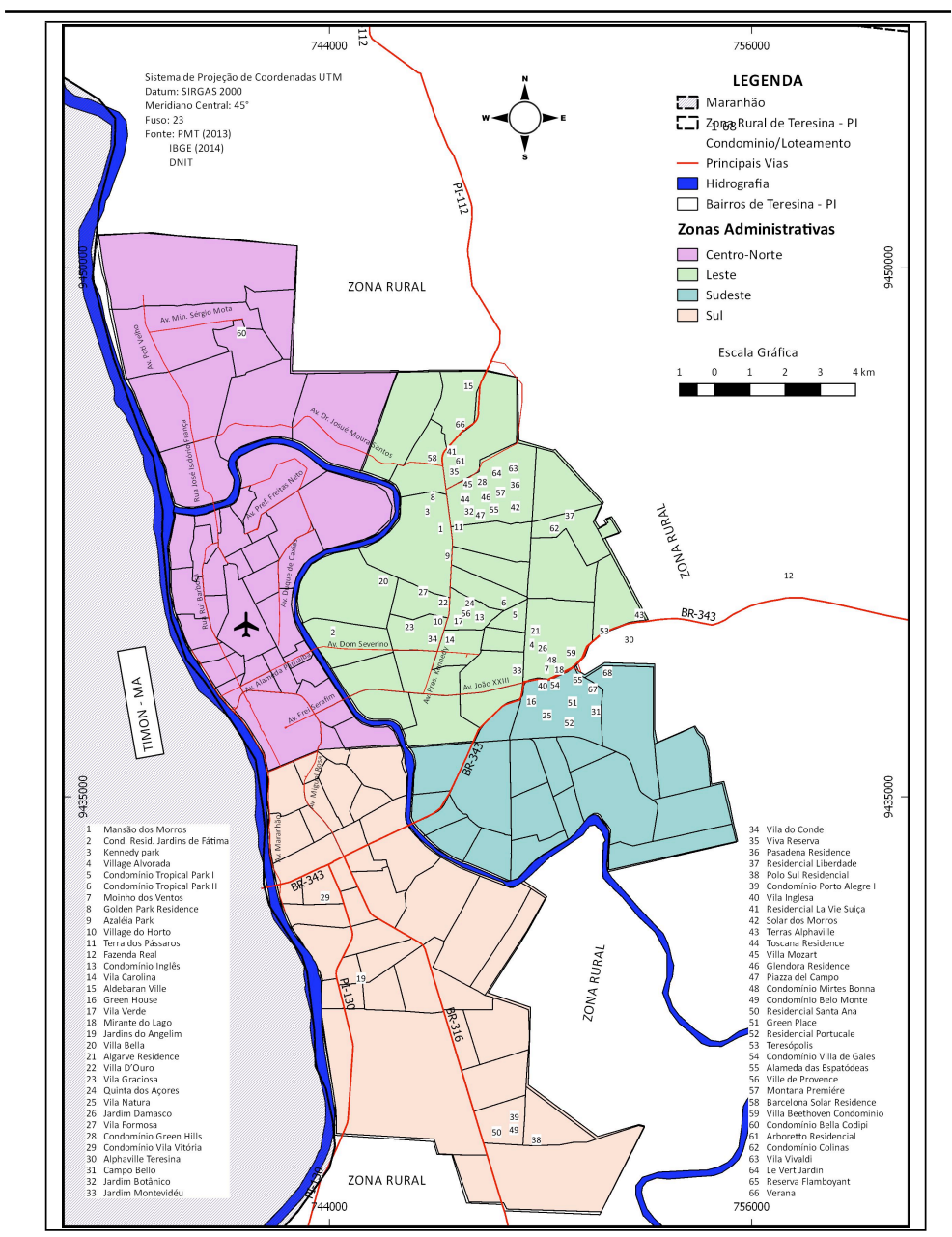

Os loteamentos fechados estão presentes em áreas periféricas da cidade, como o Mansão dos Morros, Kennedy Park, Aldebaran Ville, Mirante do Lago, Terras Alphaville Teresina, Terra dos Pássaros, Verana. A implantação desses empreendimentos se deve pela quantidade de vazios urbanos, que surgiram entre a área 
SILVA. G.C. et al. Presença de condomínios horizontais e loteamentos ...

urbana consolidada e os conjuntos habitacionais favorecendo a expansão urbana.

A maioria desses projetos é desenvolvida, em Teresina, por grupos imobiliários privados, que investem neste segmento de condomínio horizontal desde 2002, como a Construtora Tropical com os condomínios Viva Reserva, Tropical Park I e II e o loteamento Terra dos Pássaros, a Construtora Estrela da Manhã com os condomínios Vila Verde, Vila Graciosa, Vila Formosa e Vila Vitória, ambas atuando como incorporadoras.

Com o aumento da demanda no mercado de moradias houve o surgimento de novas empresas na cidade, como a Penta Incorporadora, InPacta Incorporadora (Arboretto Residencial e Reserva Flamboyant), RTF Construções (Villa Vivaldi Residence), Arte Construções (Gramado Park Residence).

As incorporadoras TerraPlan Construtora e Incorporadora Ltda (Green Place Condomínio), Cipasa Urbanismo (Verana), Penta Incorporadora (La Vie Suiça), Alphaville Urbanismo atuam em Teresina e em outros estados brasileiros. Segundo Correa (1989, p. 13), essas empresas se apropriam da terra, transformandoa em renda a partir do momento que "compram, especulam, financiam, administram e produzem espaço urbano".

Por ser um empreendimento planejado, o mercado visualiza o potencial dessas áreas para atraírem o mercado consumidor. Para Hermann e Haddad (2005), a escolha de moradia engloba o que existe dentro do condomínio e a interferência da vizinhança do entorno na qualidade do imóvel, o que afeta no valor de locação.

A construção desses condomínios pode valorizar o entorno das áreas em que foram implantados. Como exemplo disso, tem-se o Aldebaran Ville, cujo lançamento induziu a duplicação da Avenida Kennedy, que dá acesso ao condomínio. Dessa forma, além de valorizar toda a região, foi incentivada a implantação de estrutura de serviços, centros comerciais, hospitais, clínicas, instituições de ensino e de casas noturnas.

O loteamento fechado Fazenda Real Residence, embora situado na zona rural de Teresina, com a Lei 4.281/2012 foi 
SILVA. G.C. et al. Presença de condomínios horizontais e loteamentos ...

considerado pertencente à zona urbana, como Zona Residencial 2 (ZR2), de baixa densidade com lotes de médio porte (TERESINA, 2012).

Em 2010, foi lançado o primeiro loteamento fechado do Alphaville Urbanismo S.A. em Teresina e da Zona Sudeste, com lotes residenciais e comerciais e uma grande infraestrutura na área de lazer. O Terras Alphaville Teresina é o maior loteamento fechado e o segundo empreendimento do Alphaville Urbanismo S.A. da cidade, possuindo lotes residenciais, comerciais e de multiuso.

Alguns desses empreendimentos estão presentes em outras capitais brasileiras, como a Fazenda Real, que pode ser encontrado em João Pessoa, Fortaleza e Natal e o Alphaville Urbanismo S.A., presente em 21 estados brasileiros. Isso mostra que a capital teresinense tem uma demanda solvável para esses empreendimentos de alto padrão nacional.

Após 22 anos da construção do primeiro loteamento fechado de Teresina, foi lançado, na Zona Norte, o Condomínio Bella Codipi, que é um loteamento fechado, situado em uma área consolidada de serviços, infraestrutura e de fácil acesso, facilitado pela construção da Ponte Leonel Brizola, que liga a Zona Norte a Zona Leste. Esta área está em expansão, principalmente o bairro Santa Maria da Codipi, com a construção do campus do Instituto Federal de Educação, Ciência e Tecnologia do Piauí (IFPI), de bairros planejados e de conjuntos habitacionais financiados pelo Programa de Aceleração do Crescimento (PAC).

No Quadro 1 estão listados os 68 empreendimentos existentes em Teresina dispostos por zona administrativa e quantidades de unidades e ano de implantação.

Quadro 1: Condomínios horizontais fechados e loteamentos fechados existentes em Teresina, Piauí

\begin{tabular}{|l|c|c|c|}
\hline $\mathbf{N}^{\mathbf{0}}$ & Nome do empreendimento & Ano & Quantidade casas/lotes \\
\hline \multicolumn{4}{|c|}{ Zona Leste } \\
\hline 1 & Mansão dos Morros & 1991 & 107 lotes \\
\hline
\end{tabular}


SILVA. G.C. et al. Presença de condomínios horizontais e loteamentos ...

\begin{tabular}{|l|l|c|c|}
\hline 2 & Cond. Resid. Jardins de & 1997 & 22 casas térreas e 2 duplex \\
\hline 3 & Kátima & 1999 & 68 lotes \\
\hline 4 & Village Alvorada & 2000 & 6 casas térreas e 18 duplex \\
\hline 5 & Cond. Tropical Park I & 2002 & 24 casas duplex \\
\hline 6 & Cond. Tropical Park II & 2002 & 17 casas duplex \\
\hline 7 & Moinho dos Ventos & 2003 & 17 casas duplex \\
\hline 8 & Golden Park Residence & 2003 & 20 casas duplex \\
\hline 9 & Azaléia Park & 2004 & 19 casas duplex \\
\hline 10 & Village do Horto & 2004 & 07 casas duplex \\
\hline 11 & Terra dos Pássaros & 2004 & 125 lotes \\
\hline 12 & Fazenda Real Residence & 2006 & 土00 lotes \\
\hline 13 & Condomínio Inglês & 2006 & 20 casas térreas \\
\hline 14 & Vila Carolina & 2006 & 22 casas térreas \\
\hline 15 & Aldebaran Ville & 2006 & 500 lotes \\
\hline 17 & Vila Verde & 2007 & 34 casas térreas \\
\hline 18 & Mirante do Lago & 2007 & 97 lotes \\
\hline 20 & Villa Bella & 2008 & 12 casas duplex \\
\hline 21 & Algarve Residence & 2008 & 21 casas duplex \\
\hline 22 & Villa D’Ouro & 2008 & 30 casas duplex \\
\hline 23 & Vila Graciosa & 2008 & 23 casas duplex \\
\hline 24 & Quinta dos Açores & 2008 & 44 casas duplex \\
\hline 26 & Jardim Damasco & 2009 & 48 casas duplex \\
\hline 27 & Vila Formosa & 2010 & 29 casas duplex \\
\hline 28 & Condomínio Green Hills & 2010 & 28 casas duplex \\
\hline 32 & Jardim Botânico & 2011 & 10 casas duplex \\
\hline 33 & Jardim Montevidéu & 2011 & 25 casas duplex \\
\hline 34 & Vila do Conde & 2011 & 15 casas duplex \\
\hline 35 & Viva Reserva & 2011 & 36 casas duplex \\
\hline 36 & Pasadena Residence & 2011 & 40 casas duplex \\
\hline 37 & Residencial Liberdade & 2011 & 12 casas térreas \\
\hline 41 & Residencial La Vie Suiça & 2012 & 39 casas duplex \\
\hline 42 & Solar dos Morros & 2012 & 30 casas duplex \\
\hline 43 & Terras Alphaville Teresina & 2012 & 1.075 lotes \\
\hline 44 & Toscana Residence & 2012 & 40 casas duplex \\
\hline & & & \\
\hline
\end{tabular}


SILVA. G.C. et al. Presença de condomínios horizontais e loteamentos ...

\begin{tabular}{|c|c|c|c|}
\hline 45 & Villa Mozart & 2012 & 40 casas duplex \\
\hline 46 & Glendora Residence & 2012 & 16 casas duplex \\
\hline 47 & Piazza del Campo & 2012 & 35 casas duplex \\
\hline 48 & Cond. Mirtes Bonna & 2012 & 05 casas duplex \\
\hline 55 & Alameda das Espatódeas & 2013 & 25 casas duplex \\
\hline 56 & Ville de Provence & 2013 & 17 casas duplex \\
\hline 57 & Montana Premiére & 2013 & 30 casas duplex \\
\hline 58 & Barcelona Solar Residence & 2013 & 50 casas duplex \\
\hline 59 & Villa Beethoven Cond. & 2013 & 82 casas duplex \\
\hline 61 & Arboretto Residencial & 2014 & 21 casas duplex \\
\hline 62 & Condomínio Colinas & 2014 & 22 casas térreas \\
\hline 63 & Villa Vivaldi Residence & 2014 & 90 casas duplex \\
\hline 64 & La Vert Jardin & 2014 & 17 casas duplex \\
\hline 66 & Verana & 2014 & 305 lotes \\
\hline \multicolumn{4}{|c|}{ Zona Sudeste } \\
\hline 16 & Green House & 2006 & 32 casas duplex \\
\hline 25 & Vila Natura & 2008 & 32 casas duplex \\
\hline 30 & Alphaville Teresina & 2010 & 757 lotes \\
\hline 31 & Campo Bello & 2010 & 66 casas térreas \\
\hline 40 & Vila Inglesa & 2011 & 25 casas duplex \\
\hline 51 & Green Place & 2012 & 28 casas duplex \\
\hline 52 & Residencial Portucale & 2012 & 26 casas duplex \\
\hline 53 & Teresópolis & 2012 & 26 lotes \\
\hline 54 & Cond. Villa de Gales & 2012 & 24 casas duplex \\
\hline 65 & Reserva Flamboyant & 2014 & 59 casas duplex \\
\hline 67 & Villa Válega & 2014 & 35 casas duplex \\
\hline 68 & Gramado Park Residence & 2014 & 62 casas duplex \\
\hline \multicolumn{4}{|c|}{ Zona Sul } \\
\hline 19 & Jardins do Angelim & 2008 & 33 casas térreas \\
\hline 29 & Condomínio Vila Vitória & 2010 & 150 casas térreas \\
\hline 38 & Polo Sul Residencial & 2011 & 45 casas térreas \\
\hline 39 & Cond. Porto Alegre I & 2011 & 26 casas térreas \\
\hline 49 & Cond. Belo Monte & 2012 & 26 casas térreas \\
\hline 50 & Residencial Santa Ana & 2012 & 23 casas térreas \\
\hline \multicolumn{4}{|c|}{ Zona Norte } \\
\hline
\end{tabular}


SILVA. G.C. et al. Presença de condomínios horizontais e loteamentos ...

\begin{tabular}{|l|l|c|c|}
\hline 60 & Bella Codipi & 2013 & 176 lotes \\
\hline
\end{tabular}

Fonte: Prefeitura Municipal de Teresina e Pesquisa direta, 2014.

A maioria dos condomínios horizontais fechados apresentam casas duplex e estão presentes nas Zonas Leste e Sudeste. O Condomínio Residencial Jardins de Fátima está localizado em uma área nobre, próxima da Universidade Federal do Piauí, possui salão de festa e churrasqueira. Nesse condomínio, os condôminos tem liberdade nas escolhas do tipo de moradia, podendo reformá-las sem ter que seguir um padrão, diferenciando-se dos demais condomínios horizontais fechados.

Os condomínios horizontais, geralmente, estão localizados em bairros da cidade, ocupando uma quadra e usufruindo toda infraestrutura urbana, sendo que o atrativo é a segurança privada.

Os condomínios horizontais Residencial Liberdade, Campo Bello, Jardins do Angelim, Polo Sul Residencial, Porto Alegre I, Belo Monte e Residencial Santa Ana são destinados à classe média, possuindo playground e salão de festas.

$\mathrm{Na}$ Zona Sul, todos os condomínios são de casas térreas. O Vila Vitória é o maior em extensão e em quantidade de casas, mas equiparando-se aos condomínios das Zonas Leste e Sudeste. O condomínio possui área total de $50.000 \mathrm{~m}^{2}$ e está situado no bairro Saci, onde há atividade comercial e de serviços já consolidada, fácil acesso ao centro da cidade, instituições de ensino, postos de saúde e hospitais.

Esses empreendimentos têm em comum o fato de serem formas de parcelamento da propriedade privada, concebidos por um empreendedor privado, e de gestão do espaço interno por meio de uma estrutura de decisão condominial, submetida a normas próprias.

A maioria dos empreeendimentos tem o projeto assinado por arquitetos renomados, o que confere marca de autenticidade e, consequentemente, valorização dos condomínios e loteamentos.

Pode-se constatar que a consolidação dos condomínios horizontais e loteamentos fechados em Teresina ocorrem devido à 
SILVA. G.C. et al. Presença de condomínios horizontais e loteamentos ...

representatividade de morar em áreas cercadas, envolvendo segmentos de alto e médio poder aquisitivo. Estes empreendimentos se encontram em áreas com acesso rápido ao centro urbano e onde as amenidades são valorizadas em campanhas publicitárias, conseguindo valorizar e aumentar seu valor no mercado imobiliário.

Os condomínios horizontais e loteamentos fechados estão presentes em outros municípios do Piauí, como em Parnaíba, Campo Maior, Piripiri, Floriano, Uruçuí, São Raimundo Nonato, Picos e Bom Jesus. Percebe-se que as cidades de médio e pequeno porte do Piauí também estão investindo nos condomínios horizontais e loteamentos fechados por ser um produto imobiliário em expansão nas cidades brasileiras.

\section{Considerações finais}

A modalidade de condomínios horizontais se expandiu em todo território mundial como nova alternativa de moradia para as pessoas de médio e alto poder aquisitivo. São espaços planejados, que prometem, principalmente, segurança, sendo esta a razão apontada como uma das principais motivações para a escolha por esses empreendimentos.

A expansão dos condomínios horizontais e loteamentos fechados acabam gerando impactos nas cidades, destacando-se o abandono do espaço urbano público e a segregação social urbana quando o acesso a esses espaços é restrito. Estão localizados em área com amenidades, que são enfocadas em campanhas publicitárias, fazendo com que haja homogeneização social e status, a quem mora nos condomínios.

A maioria desses empreendimentos está presente na Zona Leste, considerada uma área nobre, por apresentar uma população com maior renda e uma área com melhor infraestrutura de serviços, em que empresas escolhem para se estabelecerem exercendo, assim, grande influência na distribuição de bens e na gestão urbana, tornando-se uma área atrativa para os condomínios horizontais e loteamentos fechados de maior valor ser construídos. 
SILVA. G.C. et al. Presença de condomínios horizontais e loteamentos ...

\section{Referências bibliográficas}

ABREU, Irlane Gonçalves de. $O$ crescimento da Zona Leste de Teresina - um caso de segregação? 1983, 109 f. Tese (Doutorado em Geografia). Universidade Federal do Rio de Janeiro. Instituto de Geociências, 1983.

ARAÚJO, C. C. Trilhas e estradas: a formação dos bairros Fátima e Jockey Clube (1960 - 1980). Dissertação (Mestrado em História do Brasil) - Universidade Federal do Piauí. Teresina, 2009.

BARBOSA, A. G.; COSTA, A. A. da. Implicações socioespaciais, econômicas e jurídicas em condomínios fechados horizontais. Mercator. Fortaleza, v.10, n. 2, p. 49-61, 2011.

BARCELlOS, T.; MAMMARELLA, R. O Significado dos Condomínios Fechados no Processo de Segregação Espacial nas Metrópoles. Secretaria do Planejamento e Gestão, Governo do Estado do Rio Grande do Sul, 2007 (Texto para discussão, n. 19).

BERNARDES, G. D.; SOARES JÚNIOR, A. A. Condomínios horizontais fechados: reflexão sobre a configuração do espaço intrametropolitano de Goiânia. Sociedade e Cultura, v. 10, n. 2, jul./dez., p. 209-225, 2007.

BLAKELY, E. J.; SNYDER, M. G. Fortress America: gated communities in the United States. Washington: Brookings Institution Press, 1997.

CALDEIRA, T. P. Cidade de Muros: crime, segregação e cidadania em São Paulo. São Paulo: Edusp e Editora 34, 2003.

CASTELlS, M. A questão urbana. Rio de janeiro: Paz e Terra, 1983. 
SILVA. G.C. et al. Presença de condomínios horizontais e loteamentos ...

CASTELO BRANCO, Antonio Frederico Vilarinho. A ação do estado e do mercado imobiliário no processo de segregação socioespacial em bairros da zona leste de Teresina. 2012. $109 \mathrm{f}$. Tese (Doutorado em Geografia). Instituto de Geociências e Ciências Exatas, Rio Claro, São Paulo, 2012.

CEPRO - Fundação Centro de Pesquisas Econômicas e Sociais do Piauí. Perfil dos municípios. Teresina: Fundação CEPRO, 1992.

CORRÊA, R. L. O espaço urbano. São Paulo: Ed. Ática, 1989.

FAÇANHA, A. C. A evolução Urbana de Teresina: agentes, processos e formas espaciais. Recife. Dissertação (Mestrado em Geografia). Universidade Federal de Pernambuco, 1998.

FRÚGOLI JÚNIOR, H. São Paulo: espaços públicos e interação social. São Paulo: Marco Zero, 1995.

GOMES, J. A. G. Teresina ontem e hoje. Teresina: Fundação Cultural Monsenhor Chaves, 1992.

HERMANN, B. M.; HADDAD, E. A. Mercado imobiliário e amenidades urbanas. Est. Econ., São Paulo, v. 35, n. 2, p. 237-269, abr./jun. 2005.

IBGE - Instituto Brasileiro de Geografia (2010). Cidades

KALLAS, L. M. E. Desenhando com o clima e a vegetação: Um estudo de caso do loteamento HBB em Teresina - PI. Dissertação (Mestrado em Arquitetura e Urbanismo), Universidade de Brasília - UNB, Brasília, 2008.

$\mathrm{KOCH}, \mathrm{M}$. R. Condomínios fechados: as novas configurações do urbano e a dinâmica imobiliária. Indicadores Econômicos FEE. Porto Alegre, v. 35, n. 3, p. 99-116, 2008. 
SILVA. G.C. et al. Presença de condomínios horizontais e loteamentos ...

LE GOIX, R. Gated communities: Sprawl and social segregation in southern California. Housing Studies, v. 20, n. 2, p. 323-344, 2004.

LIMA, I. M. de M. F. Teresina: Urbanização e Meio Ambiente. Scientia et Spes. Teresina, ano 1, n. 2, p. 181-206, 2002.

MARX, M. Cidade brasileira. São Paulo: Melhoramentos/ Ed. da Universidade de São Paulo, 1980.

NASCIMENTO, F. A. A cidade sob o fogo: modernização e violência policial em Teresina (1937-1945). Teresina: Fundação Monsenhor Chaves, 2002.

NEGRI, S. M. Segregação Sócio-Espacial: Alguns Conceitos e Análises. Coletâneas do nosso tempo. Rondonópolis, MT, ano 7, v. 8 , n. 8 , p. $129-153,2008$.

O’NEILL, M. M. V. C. Condomínios exclusivos: um estudo de caso. Revista Brasileira de Geografia, ano 48, n. 1, p. 63-81, 1986.

PINTO, Victor Carvalho. Condomínios horizontais e loteamentos fechados: proposta de regulamentação. Boletim de Direito Imobiliário, v. 24, p. 1-6, 2004.

ROLNIK, R. A lógica da desordem. Le Monde Diplomatique Brasil, ano 2, n.13, ago. p. 1-5, 2008.

SILVEIRA, P. F. Condomínio fechado, associação de moradores e lei municipal. 2011. Disponível em: <http:// www.migalhas.com.br/dePeso/16,MI126401,51045-Condominio + fechado + associacao + de + moradores $+\mathrm{e}+$ lei + municipal $>$. Acesso em: 7 set. 2012. 
SILVA. G.C. et al. Presença de condomínios horizontais e loteamentos ...

SOUZA, M. L. de. Fobópole: o medo generalizado e a militarização da questão urbana. Rio de Janeiro: Bertrand Brasil, 2008.

SPOSITO, M. E. B. A cidade dentro da cidade: uma Edge City em São José do Rio Preto. Scripta Nova (Barcelona), Barcelona, v. VII, n. 146 (045), p. 1-15, 2003.

TERESINA. Secretaria Municipal de Planejamento. Lei $\mathbf{n}^{\circ} 4.281$ - 2012. Teresina: Prefeitura Municipal de Teresina.

TERESINA. Teresina em dados. Prefeitura Municipal de Teresina. Teresina, 2005.

Lei Complementar $\mathbf{N}^{0}$ 3.561, de 20 de outubro de 2006. Dispõe sobre o parcelamento do solo urbano do Município de Teresina e dá outras providências. 2006.

VIANA, B. A. da S. O sentido da cidade: entre a evolução urbana e o processo de verticalização. Carta CEPRO, Teresina - PI, v. 23, n. 1, p. $66-75,2005$.

VILLAÇA, F. Espaço intra-urbano no Brasil. São Paulo: Studio Nobel, 2001.

Recebido em janeiro de 2014 Aceito em novembro de 2014 